\title{
Comment on "Clinical Profile and Outcome of Japanese Encephalitis in Children Admitted with Acute Encephalitis Syndrome"
}

\author{
Girish Chandra Bhatt ${ }^{1}$ and Tanya Sharma ${ }^{2}$ \\ ${ }^{1}$ Department of Pediatrics, All India Institute of Medical Sciences (AIIMS), Room No. 10, Saket Nagar, Bhopal, \\ Madhya Pradesh 462024, India \\ ${ }^{2}$ Department of Pathology, All India Institute of Medical Sciences (AIIMS), Bhopal, Madhya Pradesh, India
}

Correspondence should be addressed to Girish Chandra Bhatt; drgcbhatt@gmail.com

Received 23 July 2014; Accepted 19 August 2014; Published 27 August 2014

Academic Editor: Edouard Cantin

Copyright (C) 2014 G. C. Bhatt and T. Sharma. This is an open access article distributed under the Creative Commons Attribution License, which permits unrestricted use, distribution, and reproduction in any medium, provided the original work is properly cited.

We read with great interest the article by Kakoti et al. [1] and have the following comments to offer.

Out of 223 hospitalized acute encephalitis syndrome patients, 30\% (67) were diagnosed as confirmed Japanese encephalitis (JE). In the recent studies enteroviruses (EVs) are being identified as one of the common causes of encephalitis in children worldwide [2,3]. Various studies from India, Kuwait, and European countries report the prevalence of EV in encephalitis cases to be as high as $21-22 \%$ in encephalitis endemic area. Though the authors have tested samples for other flaviviruses such as dengue and West Nile viruses, it is surprising that these samples were not tested for the commoner enteroviruses.

Secondly, authors have nicely outlined the clinicodemographic profile of JE patients. However, it is surprising to find that the recently reported nonneurological manifestations of JE are lacking in the paper. Hepatomegaly, splenomegaly, deranged liver function tests, deranged renal function tests, thrombocytopenia, and so forth have been reported in JE patients [4, 5]. Some authors have suggested a possible change in virulence of JE virus or strain variation over time, developing properties similar to dengue like flaviviruses, responsible for these manifestations [5].

\section{Conflict of Interests}

The authors declare that there is no conflict of interests regarding the publication of this paper.

\section{References}

[1] G. Kakoti, P. Dutta, B. R. Das, J. Borah, and J. Mahanta, "Clinical profile and outcome of Japanese Encephalitis in children admitted with acute encephalitis syndrome," BioMed Research International, vol. 2013, Article ID 152656, 5 pages, 2013.

[2] A. Dalwai, S. Ahmad, A. Pacsa, and W. Al-Nakib, "Echovirus type 9 is an important cause of viral encephalitis among infants and young children in Kuwait," Journal of Clinical Virology, vol. 44, no. 1, pp. 48-51, 2009.

[3] G. N. Sapkal, V. P. Bondre, P. V. Fulmali et al., "Enteroviruses in patients with acute encephalitis, Uttar Pradesh, India," Emerging Infectious Diseases, vol. 15, no. 2, pp. 295-298, 2009.

[4] G. C. Bhatt, V. P. Bondre, G. N. Sapkal et al., "Changing clinicolaboratory profile of encephalitis patients in the eastern Uttar Pradesh region of India," Tropical Doctor, vol. 42, no. 2, pp. 106108, 2012.

[5] R. Kumar, P. Tripathi, S. Singh, and G. Bannerji, "Clinical features in children hospitalized during the 2005 epidemic of Japanese encephalitis in Uttar Pradesh, India," Clinical Infectious Diseases, vol. 15, no. 43, pp. 123-131, 2006. 

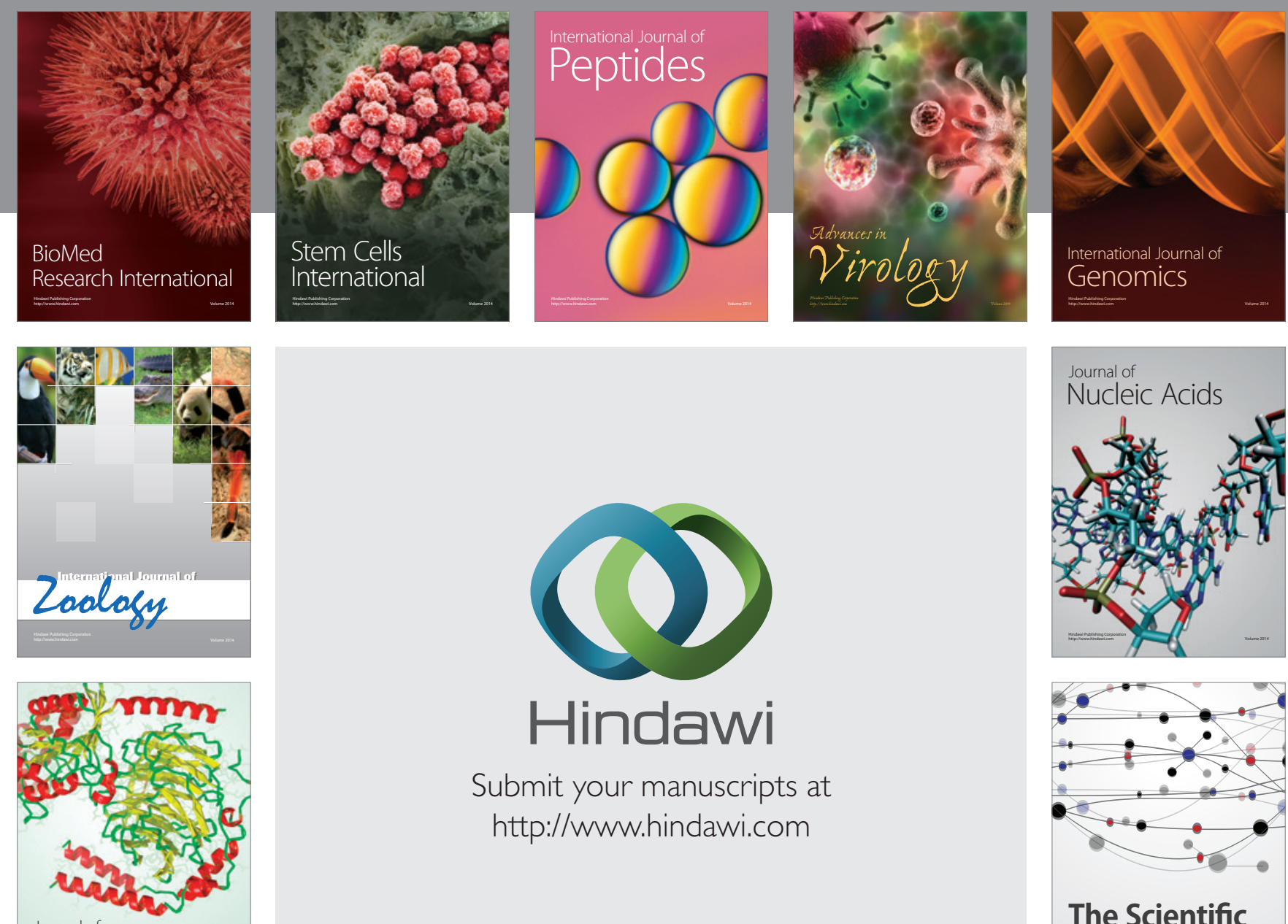

Submit your manuscripts at

http://www.hindawi.com

Journal of
Signal Transduction
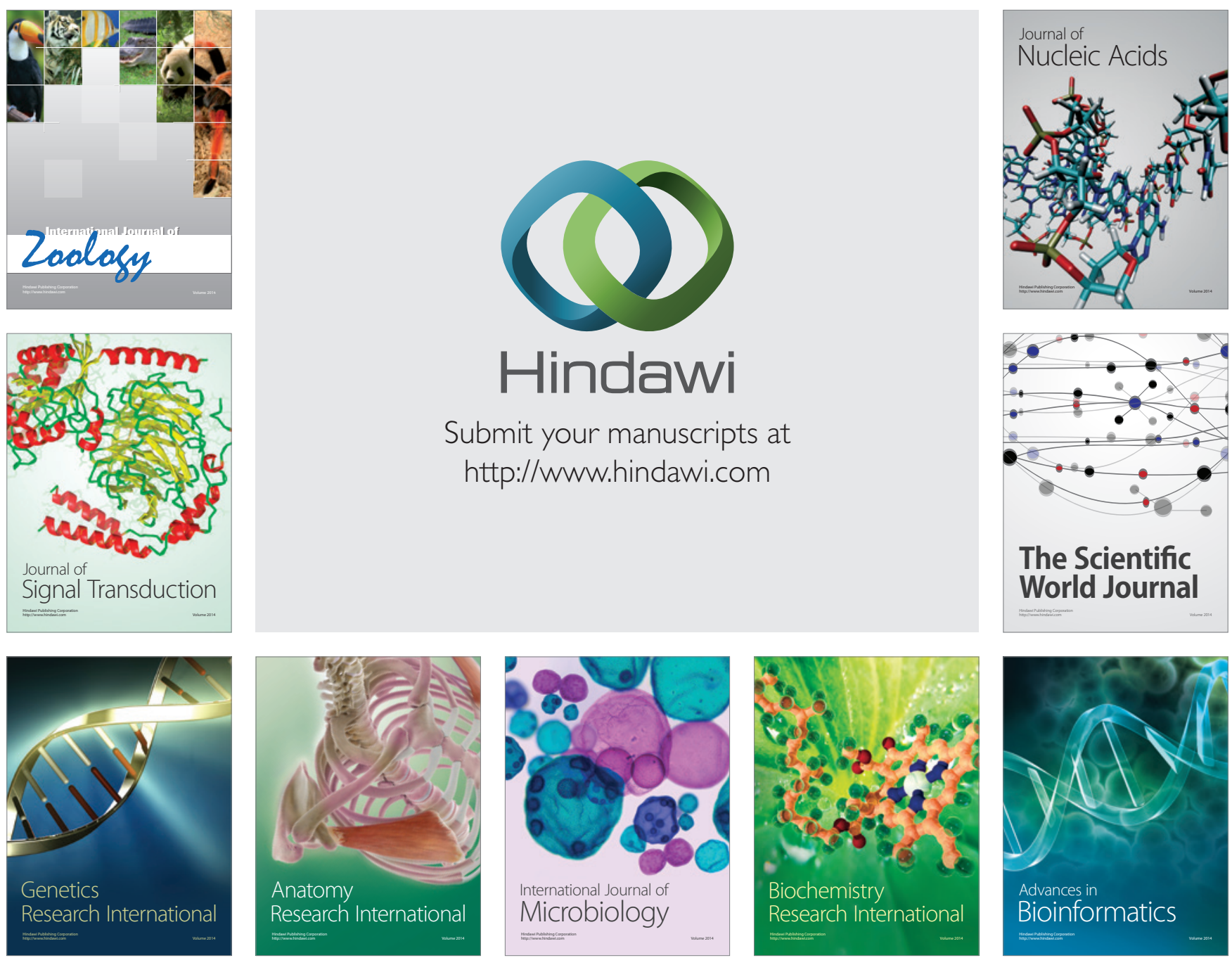

The Scientific World Journal
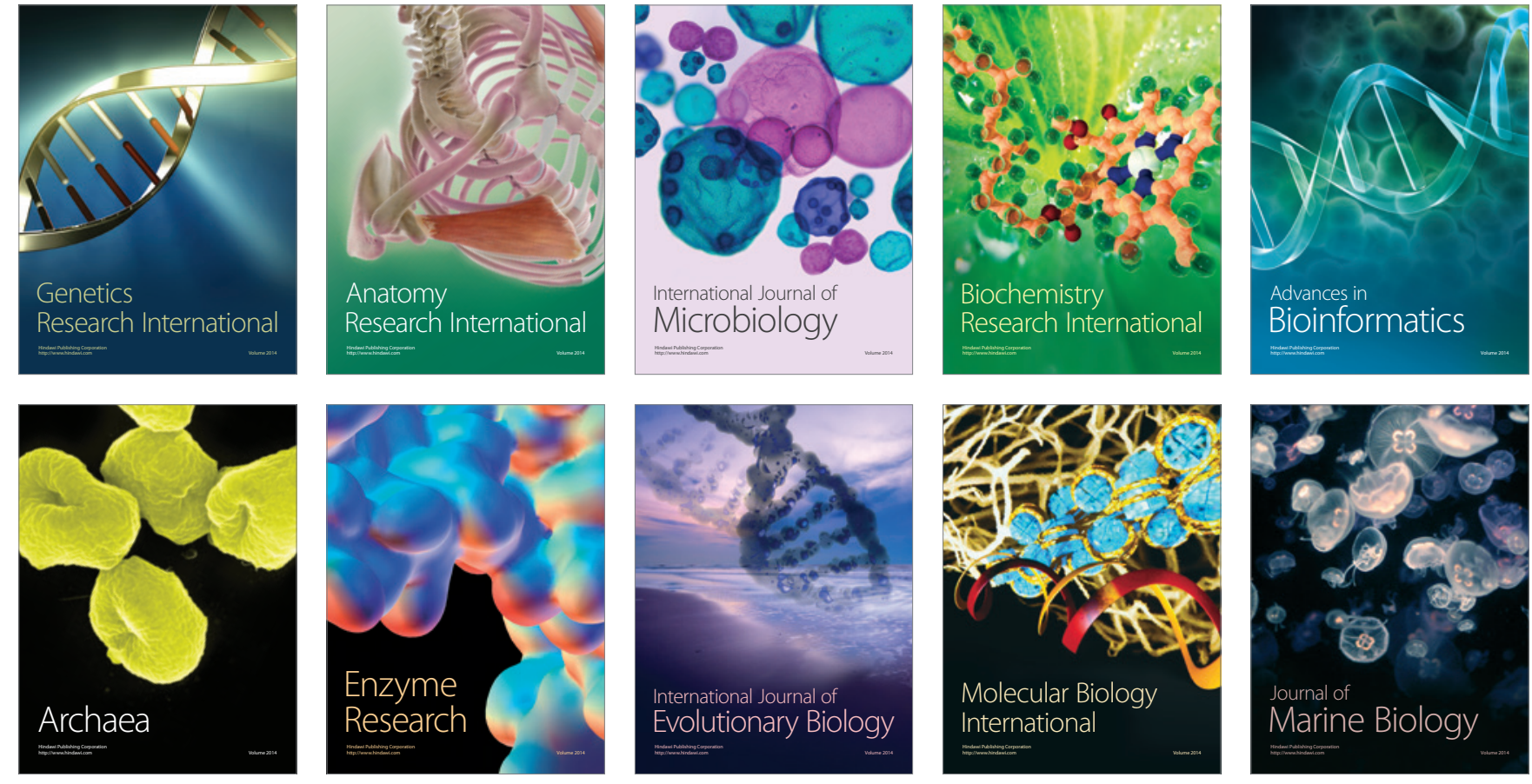